\title{
Reação de Cultivares de Feijoeiro Comum à Mancha Angular em Casa de Vegetação
}

\author{
Fabiana G. Reis-Prado ${ }^{1}$, Aloísio Sartorato ${ }^{2}$, Joaquim G.C. Costa ${ }^{2}$, Carlos A. Rava ${ }^{2}$, Sergio T. Sibov ${ }^{3}$, \\ José B. Pinheiro ${ }^{4}$ \& Monalisa S. Carneiro ${ }^{5}$
}

'Escola de Agronomia e Tecnologia de Alimentos, Universidade Federal de Goiás, CEP 74001-970, Goiânia, GO; ${ }^{2}$ Embrapa Arroz e Feijão, CEP 75375-000, Santo Antonio de Goiás, GO; ${ }^{3}$ Universidade Estadual de Goiás, CEP 75110-390, Anápolis, GO; ${ }^{4}$ Departamento de Genética, ESALQ, Universidade de São Paulo, CEP 13418-900, Piracicaba, SP;

${ }^{5}$ Instituto de Ciências Biológicas, Universidade Federal de Goiás, CEP 74001-970, Goiânia, GO, e-mail: monalisa@icb.ufg.br

(Aceito para publicação em 08/05/2006)

Autor para corrrespondência: Joaquim G.C. Costa

REIS-PRADO, F.G., SARTORATO, A., COSTA, J.G.C., RAVA, C.A., SIBOV, S.T., PINHEIRO, J.B. \& CARNEIRO, M.S. Reação de cultivares de feijoeiro comum à mancha angular em casa de vegetação. Fitopatologia Brasileira 31:306-309. 2006.

\section{RESUMO}

Foi avaliada a reação de 23 genótipos de feijoeiro comum (Phaseolus vulgaris) à mancha angular causada por Phaeoisariopsis griseola, utilizando os isolados monospóricos Ig 664 e Ig 669, caracterizados como os patótipos 63.23 e 63.19, respectivamente. Quatorze dias após a semeadura (estádio V3), as plantas foram inoculadas com uma suspensão contendo 2,5 x $10^{4}$ conídios/mL, nas faces adaxial e abaxial da primeira folha trifoliolada. A avaliação dos sintomas foi efetuada aos 14 e 18 dias após a inoculação, utilizando-se uma escala variando de 1 (sem sintomas) a 9 ( $\geq 25 \%$ da área foliar com lesões de mancha angular). Das cultivares analisadas, BRS Valente, CNFC 10281, CNFP 10138, BRS Grafite, BRS Requinte, BRS Pontal, MAR 02, Cornell 49-242 e AND 277 foram resistentes aos dois isolados. As cultivares Carioca Rubi, CNFC 9504, CNFC 10150 e Soberano foram suscetíveis aos dois patótipos testados. O patótipo 63.23 foi o mais virulento. As novas fontes de resistência à mancha angular identificadas neste trabalho podem ser utilizadas em programas de melhoramento do feijoeiro comum, que visem incorporar resistência em novas cultivares.

Palavras-chave adicionais: resistência genética, Phaeoisariopsis griseola, Phaseolus vulgaris.

\begin{abstract}
Reaction of common bean cultivars to angular leaf spot in the greenhouse

Twenty-three common bean (Phaseolus vulgaris) genotypes were tested for reaction to angular leaf spot disease caused by Phaeoisariopsis griseola in the greenhouse. All genotypes were tested with monosporic isolates Ig 664 and Ig 669, characterized as pathotypes 63.23 and 63.19, respectively. Fourteen-day-old plants (vegetative stage V3) were inoculated with a suspension containing $2.5 \times 10^{4}$ conidia/mL. This suspension was applied to the upper and lower leaf surfaces. Disease symptoms were evaluated 14 and 18 days after inoculation by using a rating scale varying from 1 (no symptoms) to 9 ( $\geq 25 \%$ of leaf area with angular leaf spot lesions). Culivars BRS Valente, CNFC 10281, CNFP 10138, BRS Grafite, BRS Requinte, BRS Pontal, MAR 02, Cornell 49-242 and AND 277 showed resistance to both isolates. Cultivars Carioca Rubi, CNFC 9504, CNFC 10150 and Soberano were susceptible to both pathotypes. Pathotype 63.23 was the most virulent. The new resistance sources identified in this work could be used in common bean breeding programs aiming to incorporate resistance to angular leaf spot in new common bean cultivars.
\end{abstract}

Additional keywords: genetic resistance, Phaeoisariopsis griseola, Phaseolus vulgaris.

O feijoeiro comum (Phaseolus vulgaris L.) é afetado por um grande número de doenças cujos agentes causais são vírus, bactérias, fungos e nematóides (Rava, 2002). A mancha angular do feijoeiro comum, cujo agente causal é o fungo Phaeoisariopsis griseola (Sacc.) Ferraris, é uma doença que tem atraído atenção de produtores e pesquisadores devido a surtos mais precoces e intensos nos últimos anos. É uma das principais doenças desta cultura no Brasil, sendo encontrada, em maior ou menor intensidade, em todas as regiões em que esta leguminosa é cultivada
(Sartorato \& Rava, 1994; Paula Júnior \& Zambolim, 1998; Rava, 2002). As perdas de rendimento são maiores quanto mais precoce for o aparecimento da doença na cultura, podendo comprometer até $70 \%$ da produção (Mora-Brenes et al., 1983; Rava et al., 1985; Sartorato \& Rava, 1992), isso dependendo da suscetibilidade das cultivares, das condições de ambiente e da patogenicidade dos isolados (Sartorato \& Rava, 1994).

As estratégias que podem ser utilizadas para o controle dessa doença incluem as práticas culturais, a resistência 
genética e o emprego de fungicidas. Entretanto, nem as práticas culturais nem o controle químico ou a associação de ambos, apresenta uma total eficiência no seu controle. Além disto, o tratamento químico pode acarretar danos ao meio ambiente. Assim, o emprego de cultivares resistentes à mancha angular é, para o produtor, a forma mais prática e econômica de controle (Sartorato \& Rava, 1994), aliado à ausência de ônus para a produção da semente, tecnologia ambientalmente saudável e redução de custos de produtos e de aplicações. Porém, a ampla variabilidade patogênica do agente causal dificulta o desenvolvimento e o uso de cultivares com resistência (Sartorato, 2002; Mahuku et al., 2003). Deve-se salientar ainda que a durabilidade da resistência de uma cultivar dependerá da aplicação de medidas complementares de controle que contribuam para diminuir a pressão de seleção no patógeno.

Alguns trabalhos foram realizados visando identificar fontes de resistência a mancha angular (Rava et al., 1985; Sartorato et al., 1991; Sartorato \& Rava, 1992; Oliveira et al., 2004). Entretanto, em função da grande variabilidade patogênica de $P$. griseola, cultivares que se comportam como resistentes em determinadas regiões apresentamse como suscetíveis em outras (Sartorato \& Rava, 1994). Desta forma, estudos que identifiquem novas fontes, com um adequado nível de resistência, são fundamentais em programas de melhoramento de feijoeiro visando resistência a esta doença. Neste contexto, o objetivo deste trabalho foi caracterizar 23 cultivares de feijoeiro comum (Tabela 1), pertencentes ao banco de germoplasma da Embrapa Arroz e Feijão, quanto à resistência à mancha angular.

Foram utilizados dois isolados monospóricos (Ig 664 e Ig 669) pertencentes a Micoteca da Embrapa Arroz e Feijão, tendo sido caracterizados no Instituto de Biotecnologia Aplicada à Agropecuária (Bioagro) da Universidade Federal de Viçosa, respectivamente, como patótipos 63.23 e 63.19. Estes patótipos foram escolhidos devido à alta virulência e prevalência nas áreas de cultivo do feijoeiro no Brasil. A suspensão do inóculo e a inoculação foram realizadas conforme descrito por Sartorato (2002). A severidade da doença foi avaliada 14 e 18 dias após inoculação, de acordo com a escala de nove graus descrita por Schoonhoven \& Pastor-Corrales (1987). As plantas que apresentaram graus de 1 a 3 foram consideradas resistentes, de quatro a seis, intermediárias e, de 7 a 9 , suscetíveis.

No presente trabalho, do total de genótipos avaliados, nove foram resistentes ao patótipo 63.23 e doze ao 63.19. Os resultados (apresentados na Tabela 1) indicam que os genótipos BRS Valente, CNFC 10281, CNFP 10138, BRS Grafite, BRS Requinte, BRS Pontal, MAR 02, Cornell 49242 e AND 277 foram resistentes aos dois patótipos. Os genótipos CNFP 10120, 10125 e Pérola apresentaram reação de resistência ao patótipo 63.19 e intermediária ao patótipo 63.23, com grau igual a 4 , podendo ser utilizados como fontes de resistência alternativas. As cultivares Ouro Negro e Uirapuru apresentaram resistência intermediária ao patótipo 63.23, mas comportaram-se como suscetíveis quando inoculadas com o patótipo 63.19. As cultivares IAC Aruã, Magnífico e Diamante Negro mostraram reação intermediária ao patótipo 63.19; no entanto, foram susceptíveis quando testadas com o patótipo 63.23. As cultivares Carioca Rubi, CNFC 9504, CNFC 10150 e Soberano foram suscetíveis aos dois patótipos utilizados (Tabela 1).

Faleiro et al. (2001), avaliando a reação de 17 cultivares de feijoeiro comum recomendadas para Minas Gerais, demonstraram que as cultivares Pérola, Diamante Negro e Ouro Negro foram susceptíveis quando inoculadas com o patótipo 63.23. Oliveira et al. (2004) verificaram

TABELA 1 - Principais características e reação dos genótipos de feijoeiro comum avaliados quanto à resistência a dois patótipos de Phaeoisariopsis griseola

\begin{tabular}{|c|c|c|c|c|c|c|c|}
\hline \multirow{3}{*}{ Genótipos } & \multirow{3}{*}{$\begin{array}{c}\text { Conjunto } \\
\text { Gênico }^{1} \\
\end{array}$} & \multirow{3}{*}{$\begin{array}{l}\text { Tamanho da } \\
\text { semente }\end{array}$} & \multirow{3}{*}{$\begin{array}{c}\text { Tipo de } \\
\text { grão }\end{array}$} & \multicolumn{4}{|c|}{ Patótipos } \\
\hline & & & & \multicolumn{2}{|c|}{63.23} & \multicolumn{2}{|c|}{63.19} \\
\hline & & & & $\mathrm{Grau}^{3}$ & $\mathrm{CR}^{4}$ & Grau & $\mathrm{CR}$ \\
\hline IAC Aruã & M & Pequeno & Carioca & 9 & S & 5 & I \\
\hline Carioca Rubi & M & Médio & Carioca & 9 & S & 8 & $\mathrm{~S}$ \\
\hline Magnífico & M & Pequeno & Carioca & 9 & S & 5 & I \\
\hline CNFC 9504 & M & Pequeno & Carioca & 8 & S & 8 & S \\
\hline CNFP 10150 & M & Pequeno & Preto & 8 & S & 7 & S \\
\hline Soberano & M & Pequeno & Carioca & 8 & S & 9 & S \\
\hline Diamante Negro & $\mathrm{O} M$ & Pequeno & Preto & 7 & S & 6 & I \\
\hline Ouro Negro & M & Médio & Preto & 6 & I & 7 & S \\
\hline IAC Piatã & M & Pequeno & Carioca & 6 & I & 5 & I \\
\hline Uirapuru & M & Médio & Preto & 5 & I & 9 & S \\
\hline CNFP 10120 & M & Pequeno & Preto & 4 & I & 2 & $\mathrm{R}$ \\
\hline CNFC 10276 & M & Pequeno & Carioca & 4 & I & 5 & I \\
\hline CNFP 10125 & M & Pequeno & Preto & 4 & I & 2 & $\mathrm{R}$ \\
\hline Pérola & M & Médio & Carioc a & 4 & I & 2 & $\mathrm{R}$ \\
\hline BRS Valente & M & Pequeno & Preto & 3 & $\mathrm{R}$ & 2 & $\mathrm{R}$ \\
\hline CNFC 10281 & M & Pequeno & Carioca & 2 & $\mathrm{R}$ & 2 & $\mathrm{R}$ \\
\hline CNFP 10138 & M & Pequeno & Preto & 2 & $\mathrm{R}$ & 3 & $\mathrm{R}$ \\
\hline BRS Requinte & M & Pequeno & Carioca & 1 & $\mathrm{R}$ & 1 & $\mathrm{R}$ \\
\hline BRS Pontal & M & Médio & Carioca & 1 & $\mathrm{R}$ & 1 & $\mathrm{R}$ \\
\hline BRS Grafite & M & Médio & Preto & 1 & $\mathrm{R}$ & 1 & $\mathrm{R}$ \\
\hline MAR 2 & M & Pequeno & Cario ca & 1 & $\mathrm{R}$ & 2 & $\mathrm{R}$ \\
\hline Cornell 49 -242 & $\mathrm{M}$ & Pequeno & Preto & 1 & $\mathrm{R}$ & 1 & $\mathrm{R}$ \\
\hline AND 277 & $\mathrm{~A}$ & Grande & Manteigão & 1 & $\mathrm{R}$ & 2 & $\mathrm{R}$ \\
\hline
\end{tabular}

${ }^{1}$ Conjunto Gênico: $\mathrm{M}=$ mesoamericano, $\mathrm{A}=$ andino; ${ }^{2}$ Tamanho da semente: Pequeno $=$ peso de 100 sementes $<25$ gramas; Médio $=$ peso de 100 sementes $\geq 25$ gramas e $\leq 40$ gramas; Grande $=$ peso de 100 sementes $>40$ gramas. ${ }^{3} \mathrm{Grau}$, definido de acordo com escala de Schoonhoven \& PastorCorrales (1987). ${ }^{4} \mathrm{CR}=$ Classes de reação: resistente $(\mathrm{R})$, graus de 1 a 3 ; intermediária (I), graus de 4 a 6; suscetível (S), graus de 7 a 9. 
que a cultivar Diamante Negro foi susceptível ao patótipo 63.19. Confirmando os dados obtidos por Faleiro et al. (2001) no presente trabalho, a cultivar Diamante Negro foi susceptível ao patótipo 63.23. No entanto, foi considerado de resistência intermediária ao patótipo 63.19, o que diverge dos resultados encontrados por Oliveira et al. (2004). As cultivares Ouro Negro e Pérola apresentaram resistência intermediária ao patótipo 63.23, o que é discordante dos resultados obtidos por Faleiro et al. (2001). Sartorato \& Rava (1994), em testes realizados em campo, constataram que a cultivar Ouro Negro apresentou resistência moderada a esse patótipo. De um modo geral, as divergências entre os resultados obtidos podem ser devidas a diferenças nas metodologias empregadas nos diferentes experimentos, como por exemplo, número de plantas avaliadas/genótipo e diferenças de temperatura e umidade durante o período de incubação. Os isolados testados por Oliveira et al. (2004) patótipo 63.19 e por Faleiro et al. (2001) patótipo 63.23 foram os mesmos dada a importância econômica do tipo de grão carioca para várias regiões brasileiras, deve-se destacar que no presente estudo foram identificadas novas fontes de resistência à mancha angular com esse tipo de grão como BRS Requinte e BRS Pontal. Com grãos do tipo preto, além da cultivares BRS Valente, destacaram-se como novas fontes de resistência CNFP 10138 e BRS Grafite. As cultivares BRS Grafite, BRS Requinte e BRS Pontal podem ser úteis em programas de retrocruzamento que utilizam cultivares mesoamericanas como genitores recorrentes, tendo em vista a relativa facilidade de transferência de genes entre indivíduos do mesmo conjunto gênico. Resultados obtidos em outros trabalhos (Rava et al., 2003; Faria et al. 2003; Peloso et al., 2003) indicam que estas cultivares (BRS Grafite, BRS Requinte e BRS Pontal) apresentam resistência a pelo menos quatro raças de Colletotrichum lindemuthianum (Sacc. \& Magnus) Briosi \& Cavara e também ao vírus mosaico dourado do feijoeiro.

A identificação destas novas fontes de resistência é importante para os programas de melhoramento genético do feijoeiro por ser a mancha angular uma doença de difícil controle, mas também por permitir um direcionamento mais eficiente de cruzamentos entre genitores resistentes e suscetíveis que poderão resultar na seleção de novas cultivares resistentes e de ampla aceitação junto aos produtores.

\section{AGRADECIMENTOS}

Ao CNPq pela concessão da bolsa de mestrado a $\mathrm{F}$. G. Reis-Prado. Este trabalho recebeu apoio financeiro da Secretaria de Ciência e Tecnologia do Estado de Goiás.

\section{REFERÊNCIAS BIBLIOGRÁFICAS}

FARIA, L.C., COSTA, J.G.C., RAVA, C.A., PELOSO, M.J.D., MELO, L.C., CARNEIRO, G.E.S., SOARES, D.M., DÍAZ, J.L. C., ABREU, A.F.B., FARIA, J.C., SARTORATO, A., SILVA, H.T., BASSINELLO, P.Z. \& ZIMMERMANN, F.J.P. BRS Requinte: nova cultivar de feijoeiro comum de tipo de grão carioca com retardamento do escurecimento do grão. 1.ed. Comunicado Técnico, 65. Santo Antônio de Goiás, GO. EMBRAPA Arroz e Feijão. 2003.

FALEIRO, F.G., NIETSCHE, S., RAGAGNIN, V.A., BORÉM, A., MOREIRA, M.A. \& BARROS, E.G. Resistência de cultivares de feijoeiro-comum à ferrugem e à mancha-angular em condições de casa de vegetação. Fitopatologia Brasileira 26: 86-89. 2001.

MAHUKU, G.S., JARA, C., CAJIAO, C. \& BEEBE, S. Sources of resistance to angular leaf spot (Phaeoisariopsis griseola) in common bean core collection, wild Phaseolus vulgaris and secondary gene pool. Euphytica 130:303-313. 2003.

MORA-BRENES, B., CHAVES, G.M. \& ZAMBOLIM, L. Estimativas de perdas no rendimento do feijoeiro-comum (Phaseolus vulgaris L.) causadas pela mancha-angular (Isariopsis griseola Sacc.). Fitopatologia Brasileira 8:599. 1983. (Resumo)

OLIVEIRA, E.J., ALZATE-MARIN, A.L., BORÉM, A., MELO, C.L.P., BARROS, E.G. \& MOREIRA, M.A. Reação de cultivares de feijoeiro comum a quatro raças de Phaeoisariopsis griseola. Fitopatologia Brasileira 29:220-223. 2004.

PAULA JÚNIOR, T.J. de \& ZAMBOLIM, L. Doenças. In: Vieira, C., Paula Júnior, T. J. \& Borém, A. (Eds.) Feijão: Aspectos gerais e cultura no Estado de Minas. Viçosa, MG. Editora UFV. 1998. pp. 375-433.

PEloso, M. J. D., MELO, L.C., COSTA, J. G. C., RAVA, C. A., CARNEIRO, G. E. S., SOARES, D. M., DÍAZ, J. L. C., ABREU, A. F. B., FARIA, J.C. \& SARTORATO, A., SILVA, H. T., BASSINELLO, P. Z., ZIMMERMANN, F. J. P. BRS Pontal: Nova Cultivar de Feijoeiro Comum de Tipo de Grão Carioca com Alto Potencial Produtivo. 1.ed. Comunicado Técnico, 64. Santo Antônio de Goiás, GO. EMBRAPA Arroz e Feijão. 2003.

RAVA, C.A., COSTA, J.G.C., FARIA, L.C., PELOSO, M.J. D., CARNEIRO, G.E.S., SOARES, D.M., DÍAZ, J.L.C., MELO, L. C., ABREU, A.F.B., FARIA, J.C., SILVA, H.T., SARTORATO, A., BASSINELLO, P.Z. \& ZIMMERMANN, F.J.P. BRS Grafite: cultivar de feijoeiro comum de grão preto, indicada para as regiões Sudeste e Centro-Oeste do Brasil. 1.ed. Comunicado Técnico, 63. Santo Antônio de Goiás, GO. EMBRAPA Arroz e Feijão. 2003.

RAVA, C.A. Influência de fungicidas no controle da antracnose e da mancha angular em feijoeiro comum. Summa Phytopathologica 28:65-69. 2002.

RAVA, C.A., SARTORATO, A. \& CARVALHO, J.R.P. Yield losses in dry bean (Phaseolus vulgaris L.) caused by angular leaf spot (Isariopsis griseola Sacc.). Annual Report of Bean Improvement Cooperative 28:5-6. 1985.

SARTORATO, A. Identification of Phaeoisariopsis griseola pathotypes from five States of Brazil. Fitopatologia Brasileira 27:78-81. 2002.

SARTORATO, A. \& RAVA, C.A. Mancha angular. In: Sartorato, A. \& Rava, C.A.(Eds.) Principais Doenças do Feijoeiro Comum e seu Controle. Brasília. EMBRAPA-SPI. 1994. pp. 41.68.

SARTORATO, A. \& RAVA, C.A. Influência da cultivar e do número de inoculações na severidade da mancha angular (Isariopsis griseola) e nas perdas na produção do feijoeiro comum (Phaseolus vulgaris). Fitopatologia Brasileira 17:247-251. 1992.

SARTORATO, A., RAVA, C.A., MENTEN, J.O.M. \& BERGAMIN 
FILHO, A. Resistência vertical do feijoeiro comum (Phaseolus vulgaris L.) a Isariopsis griseola. Fitopatologia Brasileira 16: 4346. 1991.
SCHOONHOVEN, A. van \& PASTOR-CORRALES, M.A. (Comp.) Sistema estándar para la evaluación de frijol. Cali. Centro Internacional de Agricultura Tropical. 1987. 